\title{
GREEN ECONOMY AS A MECHANISM FOR IMPLEMENTING ORGANIC PRODUCTION DEVELOPMENT
}

\section{Oksana Hutsalenko ${ }^{1}$ \\ Volodimir Todosiichuk ${ }^{2}$}

DOI: https://doi.org/10.30525/978-9934-588-53-2-5

Abstract. The purpose of the study is to introduce the green economy as a mechanism for implementing the development of organic production in Ukraine. Method. To achieve this goal, we use common scientific and specific research methods: we have compared the state of green resources in Ukraine and foreign countries, analyzed the concepts and resolutions of various congresses and seminars in the field of green economy and organic production, compared with the green economy of different countries and areas of organic and of environmental production, investigated the Environmental Performance Index and Environmental Safety Indicators. Results. According to the survey, Ukraine was ranked among the ten countries with the lowest levels of security, according to experts of the World Economic Forum, taking the 127th place out of 136, along with countries such as Honduras, Kenya, Egypt, Venezuela, Nigeria, Pakistan, El Salvador, Yemen and Colombia. The Philippines, Lebanon, Mali and Bangladesh are ahead of Ukraine. Finland, the United Arab Emirates, Iceland and Oman rank first in the ranking. In total, 136 countries are rated. In terms of environmental stability, Ukraine ranks 90th, ahead of Laos, Kazakhstan and Bahrain. Switzerland, Austria and Norway are the most stable in terms of the environment. Value / originality. Ukraine has a powerful earthquake

\footnotetext{
${ }^{1}$ Candidate of Economic Sciences, Associate Professor, Head of the Department of Audit and State Control,

Vinnytsia National Agrarian University, Ukraine ORCID: https://orcid.org/0000-0001-9348-4881

ResearcherID: V-7531-2017

${ }^{2}$ Ph.D, Associate Professor, Associate Professor at the Department of Administrative Management that Alternative Energy, Vinnytsia National Agrarian University, Ukraine ORCID: https://orcid.org/0000-0002-3498-1295 ResearcherID: L-8200-2018
}

(C) Oksana Hutsalenko, Volodimir Todosiichuk 
potential. However, imperfect farming technologies, the extensive nature of agricultural production, neglect of land resources at the disposal of economic agents in the absence of a closed cycle of use, lead to a significant deterioration of the quality of land resources and aggravation of man-made problems. Every year, over one thousand hectares of disturbed lands are lost in Ukraine, which have lost their economic, ecological and economic value due to disturbance of the soil cover due to human production activity or natural factors; the permissible volumes and the list of inorganic products, substances, products obtained in the transitional period, which in exceptional cases can be used in the production of organic products (raw materials), for each of the product categories, substances shall be established by the Cabinet of Ministers of Ukraine

\section{Introduction}

Most economic development and growth strategies have encouraged the rapid accumulation of capital through the excessive depletion of natural capital, sacrificing natural resources and ecosystems. There is an urgent need to improve public policy, including pricing and regulation, to create market incentives for more rational allocation of capital from resource use to more technological sectors, taking into account the social and environmental impacts.

In 1992 at the UN Millennium Summit in Rio de Janeiro, sustainable development was recognized as a global priority for humanity. Sustainable development means a model of economic growth, in which the use of resources is aimed at meeting human needs while preserving the environment, so that these needs can be met not only now but also for future generations. The implementation of the sustainable development strategy implies a combination of economic efficiency, social stability and environmental security. In fact, until the recognition of the green economy as a mechanism for sustainable development, it remained the privilege of rich countries.

The principles of a green economy have been formulated as a mechanism for implementing a sustainable development strategy for countries of all types of political system and level of economic development. UNEP defines a "green" economy as enhancing people's well-being and ensuring social justice, while significantly reducing environmental risks and increasing poverty. 
The state of Ukraine's land resources is close to critical. Agricultural lands occupy $78 \%, 71 \%$ of which is arable land. Of the 41576000 hectares of these lands $74 \%$ are private and $26 \%$ is state. Widespread processes of land degradation, soil erosion covers $57 \%$ of the territory. More than 500 million tons of soil are washed away annually. The area of eroded land is increasing annually by more than 80000 hectares. Economic damages from erosion already exceed 10 billion USD a year. Depreciation of agricultural machinery in Ukraine is $40.7 \%$. Over the last ten years, the number of agricultural technology has halved. The policy of modernization and sustainable development of Ukraine on the basis of the «green» economy. The terms of the Agreement on Political Association of Ukraine and the EU provide for the introduction of sustainable economic development and mechanisms for a «green» economy, which is in line with the principles of the sustainable development strategy adopted at the Rio +20 UN Summit. The process of greening the economy has two dimensions: ecological modernization of the economy and the formation of new "green branches" of the economy.

Economy Sectors New Green Areas:

1. Food - introduction of eco-labeling; - development of organic agriculture - control over the cultivation, production, sale and consumption of genetically modified organisms.

2. Social - adaptation of economy and population to climate change; - improving the energy efficiency of housing; - formation of a system of sustainable consumption - systematic measures for prevention of emergencies of man-made origin.

Income and employment growth is driven by public and private investment that reduces carbon emissions and pollution, improves energy and resource efficiency, prevents biodiversity loss and promotes ecosystem services.

These investments need to be supported through targeted public spending, policy reforms and changes to the regulatory system. Such a path of development must preserve, increase and, where necessary, restore natural capital as the most important economic asset and source of public goods, especially for the poor, whose sources of income and protection depend on nature. Today, there is ample evidence that greening the economy does not hinder the creation of tangible goods or jobs, and that investing 
heavily in the green sectors is an asset for growing financial well-being and employment. However, the transition to a «green» economy requires the creation of new conditions, and this requires urgent action by governments all over the world. The policies needed to make this transition require reducing or eliminating environmentally harmful subsidies, using market incentives, improving regulation, moving to green public procurement, and stimulating investment.

\section{Economic crisis effects on consumer behavior}

According to G.A. Pasternak-Taranushchenko: "ecological security is a direction of ensuring the economic security of the state, designed to create the most favorable conditions (environment) for the population of the country to exist and to produce a fruitful life" [6]. He notes that «ecology is capable of influencing two groups of resources: labor and material.» In addition to environmental GA Pasternak-Taranushchenko also distinguishes «resource» and «freshwater» security as components of the economic security of the state. Improving the system of indicators of economic security of the state, V. Kotkovskyi included in the first of three groups of indicators those that characterize the "ecological potential of society" in the current and medium-term aspects of "economic dynamics and social development" [10]. Exploring the economic security of Ukraine in the regional context, V. Kuzmenko notes that the "components of regional economic security» is a complex of interrelated and interdependent spheres of human activity (socio-economic, scientific, technological and environmental) [9].

It should be noted that the environmental component is present in many areas of economic security. For example, in demographic (health, fertility), food (area of agricultural land, organic farming) [10], social (on the labor market are affected by environmental factors such as disturbance of human life conditions, primarily due to the Chernobyl disaster and pollution of the environment) [12]. At the same time, it is possible to distinguish purely "ecological" directions, in particular industrial and household waste management, rational environmental management, greening of production, development of competitive small and medium-sized business in the natural and economic sector [12].

There are also some specific areas related to the impact of environmental performance on the components of economic security. For example, according to V. Shcherban, the issues of ecological safety of foodstuffs, 
their quality and health benefits for the population remain the least taken into account in the basic principles of food security [30]. It should also be noted that among the main indicators of food security [8]: economic affordability of products (share of total food expenditure in total household expenditure) and differentiation of food costs by social groups (monitored in dynamics and calculated as the ratio of the cost of food 20 the highest income households and the cost of food 20 percent of the lowest income households). In our opinion, these two indicators are directly related to the socio-economic situation in the country.

The Environmental Performance Index is a global study and its accompanying ranking of countries around the world in terms of the load on the environment and the rational use of natural resources.

The index measures the country's achievements in terms of the state of ecology and natural resource management on the basis of 22 indicators in 10 categories, reflecting various aspects of the state of the environment and the viability of its ecological systems, conservation of biological diversity, combating climate change, public health, economic practice and the degree of its load on the environment, as well as the effectiveness of state policy in the field of ecology.

Environmental indicators are the main tool for assessing the state of the environment in countries of Eastern Europe, the Caucasus and Central Asia. Properly selected indicators based on sufficient time series of data (time trends) can not only reflect the main trends, but also contribute to the analysis of the causes and consequences of the environmental situation and situation. They also make it possible to monitor the progress and effectiveness of environmental policies in countries.

Depending on the role of the indicator in assessing a particular issue, the indicators are classified under the scheme of the European Environment Agency DF-P-S-I-R (DPSIR): Driving Force - Pressure - Condition Impact - Response.

DF - Driving force - socio-economic factors and activities that exacerbate or reduce environmental stress.

$\mathrm{P}$ - Preasure - direct anthropogenic load on the environment through emissions and discharges of pollutants, use of natural resources.

$\mathrm{S}$ - State - refers to the current state and trends of environmental change, including the quality parameters of the major environmental components. 
I - Impact - the effects of environmental change on public health, the effects on nature and biodiversity.

$\mathrm{R}$ - Respons - specific actions aimed at solving environmental problems.

According to the analysis of the system under this scheme, social and economic development increases the pressure on the environment and, as a consequence, causes environmental changes, for example, creating adequate conditions for health, availability of resources and biodiversity. Finally, it leads to the confrontation of human health, ecosystems and materials, which can cause a negative social response, fueled by driving forces through environmental pressures or factors directly, through adaptation or precautionary action.

\section{Survey methodology}

Ukraine has been ranked among the ten countries with the lowest levels of security, according to World Economic Forum experts, ranking 127 th out of 136, alongside countries such as Honduras, Kenya, Egypt, Venezuela, Nigeria, Pakistan, El Salvador, Yemen and Colombia. The Philippines, Lebanon, Mali and Bangladesh are ahead of Ukraine. Finland, the United Arab Emirates, Iceland and Oman rank first in the ranking. In total, 136 countries are rated. In terms of environmental stability, Ukraine ranks 90th, ahead of Laos, Kazakhstan and Bahrain. Switzerland, Austria and Norway are the most stable in terms of the environment.

On February 14, 2017, the Government approved the 2016 Progress and Performance Report of the Cabinet of Ministers of Ukraine. Reporting was carried out in accordance with the Government's 2016 Priority Action Plan for 74 priority areas, each of which set a goal, targets and specific steps that were expected to be achieved in 2016. It should be noted, as a positive, the practice of public reporting to the Government on the activities performed. In the field of ecology, the government has reported on three areas: harmonization of the Ukrainian environmental legislation with the European Union law, combating corruption and ensuring transparency of the Ministry of Environmental Protection, increasing the level of environmental safety in the exclusion zone. Of the 15 targets, the government identified $6(40 \%)$ as being implemented. The fact that the government does not use the category "not fulfilled" in its assessment, and that is why the rest of the indicators are under implementation, is notable. 
Such self-assessment of the government's activities in the environmental field could be encouraged, but a detailed reading does not agree with this. For example, the government is reported as having met a target for the introduction of the European ecological mechanism for the conservation of the habitat and species of wild fauna and flora and fauna. However, this whole environmental mechanism consists only of preparing a scheme to amend national legislation to approximate the requirements of the relevant EU directives. Neither the legislation itself nor its implementation in practice for the protection of wild birds is required, because, according to the logic of the government, the scheme of changes has already protected them. There are also reservations about further actions of the CMU.

Thus, the government envisages the drafting of the Law of Ukraine «On Amendments to the Law of Ukraine» On the Fundamental Principles (Strategy) of the State Environmental Policy of Ukraine for the Period up to 2020 «and approval of the National Environmental Action Plan for 2017-2021. The latter is accepted for implementation of the strategy, as it can be approved if only the drafting of the strategy is envisaged. The years of strategy implementation and plan implementation remain open -2020 or 2021 .

The position of the Government on the creation of a single control and oversight body in the environmental field is unclear. Because, at first, the government in the report advocates the establishment of the State Environmental Inspectorate of Ukraine, and in subsequent actions, the State Environmental Protection Service of Ukraine.

Ukraine has a powerful earthquake potential. However, imperfect farming technologies, the extensive nature of agricultural production, neglect of land resources at the disposal of economic agents in the absence of a closed cycle of use, lead to a significant deterioration of the quality of land resources and aggravation of man-made problems. Every year, more than one thousand hectares of disturbed lands are lost in Ukraine, which have lost their economic and ecological value due to disturbance of soil cover due to human production activity or natural factors. With this in mind, it is proposed to use as indicators of changes in the state of land resources: the level of land plowing ( $\%)$; the level of land degradation ( $\%$ of total area); share of natural forage in the total area of agricultural land (\%); disturbed lands $\left(\mathrm{km}^{2}\right)$; land utilized $\left(\mathrm{km}^{2}\right)$; land reclaimed $\left(\mathrm{km}^{2}\right)$. 
We are "actively" approaching the loss of land, our second strategic resource - land. The development of farms also needs to be seriously addressed through the introduction of integrated closed-loop technologies. Then Ukraine will be able to take a worthy place in the global distribution of food production, economic modernization, export potential development and raising living standards.

Family farms are the successful form of farming in many developed European countries: in Poland, Italy or the Netherlands, families own an average of 5-15 ha of land. In Ukraine, most organic growers own an area of 0.5-2 ha. One of the farms in Cherkasy region, with an area of only 2 hectares, today produces 42 types of certified organic products: greens, salads, vegetables and processed products.

Kutovoy's $3+5$ APC strategy states that organic matter is a priority for Ukraine. After all, it is a niche export-oriented product, high-margin direction. This also applies to land use, ecology, conservation of natural resources, etc. Last year, Ukraine exported cereals for 8 billion EUR, with the market for organic produce in Germany alone being valued at the same amount. By exporting raw materials, we deplete soils and do not get the proper economic effect. Instead, value-added production and organic production should be developed.

European farmers are able to develop organic farming because the state provides them with sufficient financial support. The average amount of such aid in Europe is 200-300 EUR / ha. In the first years of organic cultivation, the yield is not as high as in traditional agriculture, and the farmer will not be able to sell his produce as organic during the transitional period. There are also costs for the certification of farms, which in the European countries are partially or fully covered by the state.

By defining organic products as a priority, it is necessary to provide state financial support to organic producers and exempt them from taxation for at least the first 2-3 years of the transition period or to provide tax benefits.

A separate issue is the decline in soil fertility in Ukraine, one of the reasons being that land is not owned. It is also necessary to create effective bodies for monitoring the state of land resources.

The new version of the Bill No. 5448 of 24.11.2016 "On Amendments to Certain Legislative Acts of Ukraine on Organic Production, Circulation and Labeling of Organic Products" aims to bring Ukrainian legislation in the 
field of organic production closer to the European standards. It also gives an opportunity to set general requirements for the production of organic products in our country: requirements for crop rotation, soil cultivation, seed material, fertilization of agricultural crops, use of plant protection products. The implementation of the provisions of the draft Law should help to expand the external markets for its sale, but, first of all, it should help to increase the volume of production of such products. On the whole, the bill is progressive and European.

\section{Findings}

Over the last few years, Ukraine has become a reliable supplier of organic products to the EU countries due to its quality and competitiveness. Deputy Minister of European Integration Olha Trofimtseva said this during a conference «Organic Supply from Ukraine 2016», which took place in late October in Germany, reports the Ministry of Agriculture.

Nearly 300 farmers produce organic products that exceed domestic consumption. About 400,000 hectares of land in Ukraine are certified for organic farming. More than $80 \%$ of total exports of these products go to the EU. The Ukrainian organic products are in high demand from foreign consumers. But today, the Ukrainian exporters and the European distributors are facing a number of problems in their work.

She said that the Ministry of Agriculture would work to reduce the regulatory barriers to imports of the Ukrainian organic products to the EU countries. Today, there is a debate about the feasibility of having a double check of organic products from Ukraine and 9 other countries when exporting to the EU. The first inspection of products takes place before crossing the border by our national control authorities, and then the inspection must take place in the country of destination. These «voluntary directives» put in place by the European Commission add extra work and costs not only to domestic exporters but also to foreign buyers. Importers lose time and money through additional analysis, which affects the competitiveness of our products.

The main «homework» of the ministry will be to create a complete register of organic producers in Ukraine, which will help to have a clear and transparent picture of the organic sector of the country. According to Olha Trofimtseva, the Ministry of Agriculture is actively working on this direction. 
At present, the European colleagues in the green economy are preparing to launch a new electronic certification system for importing products.

The European Commission has proposed the creation of a new electronic certification system for imported organic products. This will help to track products during shipping for trade transparency and reduce fraud risks. The Ministry of Agriculture actively supports this proposal, as it will increase the level of confidence of foreign consumers in the quality of the Ukrainian organic products, as well as significantly reduce the level of costs for our controlling bodies.

The EU Decree on the Transition to the Electronic Certification System will come into force within 6 months and is scheduled for launch in April 2017. Production of organic products in recent years in Ukraine continues to actively develop. Over the 12 years (2003-2014), the number of Ukrainian organic producers has increased 6-fold.

For Ukraine, as a large agricultural producer, the issue of adaptation of agriculture to climate change and natural conditions of production is one of the important directions of agrarian policy formation.

In the strategy of the Ministry of Agrarian Policy, this is embedded within the Irrigation priority area, which actually covers a wider range of issues related to the formation of new approaches to environmental aspects in the agricultural and processing sectors.

Climate change is a threat to global food security, sustainable development and the achievement of the goal of poverty alleviation. Therefore, adapting agriculture to climate change, mitigating its effects and reducing greenhouse gas emissions is one of the organisation's priorities at both global and national levels.

At the request of the Ministry of Agriculture, FAO will provide technical assistance in writing the agricultural part of the National Climate Change Adaptation Strategy. In the framework of already existing projects, FAO promotes the introduction of new technologies aimed at reducing emissions and participates in projects on the development of irrigation and drainage systems at the expert level.

Organic production sites want to provide through auctions at preferential rates The Ministry of Agrarian Policy and Food and the State Agency for Geodesy, Cartography and Cadastre to develop a mechanism whereby land plots intended for organic production and grape cultivation will be granted for preferential cultivation land auctions. 
First and foremost, organic land will be used for stockpiles that have not been used for a long time. This will allow the investor to shorten the period of receipt of the certificate of conformity. The ministry added: if high demand for land is recorded in the first auctions, the practice of holding them can be expanded. The priority objectives of the Ministry of Agriculture in 2017 have been land reform, stimulating the development of the agricultural sector, improving the quality and guarantee of food safety and the development of organic production. The ministry intends to develop organic production to bring the share of such production to $3 \%$ in gross agricultural production by 2020 . As of today, $1 \%$ of arable land is used in organic production in Ukraine.

Organic is not a product but a process certification. That is, they check compliance with the standards of not one batch of production, but of the whole process of production, cultivation of land, which is not so easy to change. And which is confirmed every year. Changing the whole process in a week is simply impossible and makes no sense. Therefore, if the standard already exists, all parties will be organic.

Among the alternative management systems, organic farming practiced in 162 countries is currently the most developed. It contributes to the improvement of the quality of land resources and the environment as a whole, which has a direct positive impact on the health of the population.

The greening of agricultural production in the world is driven by the new goals proclaimed by the UN and FAO. Along with the problems of hunger, poverty, the issues of preserving agricultural land, food security and production of organic and organic products are also raised.

In 1985, the Department of Organic Farming Research formed the basis for formulating the meaning of the term «organic farming» as a system of agricultural production that prohibited or significantly restricted the use of synthetic fertilizers, pesticides, and plant growth regulators. In crop production, this system is based on the maximum and effective use of crop rotations, nutritional residues and side part of plants, manure, composts, green fertilizers, side crops, organic waste processing plants, mechanical soil cultivation and biological methods of weed control, pests, pathogens diseases. In 1995, the National Organic Standards Board proposed a slightly different definition of organic farming as «...an ecological management system for agricultural production that supports and improves biodiversity, biological 
cycles and soil biological activity.» It is based on the minimal use of unnatural (artificial) materials and raw materials and the use of agrotechnical measures that revive, support and improve environmental harmony.

As defined by the International Federation for the Development of Organic Farming (IFOAM): "Organic agriculture is a production system that supports the health of soils, ecosystems and humans. It depends on ecological processes, biodiversity and natural cycles that are specific to local conditions and, at the same time, does not allow the use of harmful resources that cause adverse effects.»

The development of agriculture is a complex organizational mechanism that requires considerable work in the previous stage of implementation. In fact, ecological farming is not just a refusal to use mineral fertilizers and chemical plant protection products, it is a whole system of rules and requirements that must be met when organizing agricultural production. Organic production and grown organic products are considered as such only after obtaining the relevant certificate of product quality, provided that all the requirements and standards of organic land use are met.

The main requirements of ecological economic production include:

1) organic production is carried out only on ecologically clean lands;

2) cultivation of crops is carried out without the use of synthetic fertilizers, genetically modified seeds and planting material, pesticide technologies;

3) application of wide-disc heavy-duty harrows and wide-cultivators to the depth of tillage 4-5 cm;

4) cultivation of crops adapted to the natural climatic and soil conditions;

5) protection of crops against diseases and pests by agrotechnical, microbiological preparations and preventive means.

Similarly, there is a set of conditions and requirements for conducting organic livestock: the refusal of permanent stalling, the mandatory grazing of animals and the refusal of the use of feed additives and hormones.

By definition, the EU Council Regulation on Organic Production and Labeling of Organic Products is a holistic food management and production system that combines best practices with regard to environmental conservation and the level of biological diversity. Conservation of natural resources, the application of high standards of the proper keeping (welfare) of animals, and a production method that meets certain requirements for products made using substances and processes of natural origin. 
Organic production characterizes the production activity of natural persons (legal entities) with a complete technological cycle: from growing organic products, processing them to obtaining a natural (environmentally friendly) product. Accordingly, the products obtained as a result of certified organic production receive the status of organic, which adds value to the products, without excluding national control over the quality of products, compliance with sanitary and hygienic norms, etc.

Only organic raw materials are used for the production of organic products, which comes from proven and certified farms to processing plants, where they are processed separately from traditional raw materials in order to avoid mixing.

Therefore, one of the important prerequisites for the development of organic farming in Ukraine is the development of a systematic regulatory framework for regulating the development of organic plant and animal husbandry, the conditions for product certification and recognition as environmentally friendly, as well as the formation and justification of a comprehensive strategy for the development of organic farming. Without systematic preparatory work, individual measures will not have the expected effect.

The United Nations Convention to Combat Desertification, which was adopted in Paris, France, on June 17, 1994, entered into force on December 26,1996 . It is on this day that the international community commemorates World Desertification Day. Ukraine acceded to the 2002 Convention in accordance with the Law of Ukraine of July 4, 2002 No. 61-IV.

According to the Decree of the Cabinet of Ministers of Ukraine of October 22, 2014 No. 1024-p, the Concept of Combating Land Degradation and Desertification was approved.

The production of organic products (raw materials) in the green economy process recognizes the production activity of natural or legal persons (including cultivation and processing), where such production excludes the use of chemical fertilizers, pesticides, genetically modified organisms (GMOs), preservatives, etc., and all stages of production (cultivation, processing) apply the methods, principles and rules laid down by the Law of Ukraine «On production and circulation of organic agricultural products and raw materials» for obtaining I have natural (environmentally friendly) products, as well as the conservation and restoration of natural resources. 


\section{Conclusions}

The production of organic products and / or raw materials uses methods that: exclude the use of GMOs, derived GMOs and products made from GMOs as food, feed, process additives, plant protection products and soil, fertilizer, seeds, vegetative origin of planting material, microorganisms and animals; exclude the use of chemically synthesized substances, preservatives, synthesized (artificial) dyes, hormones, antibiotics, flavors, stabilizers, flavor enhancers, growth promoters; exclude the use of ionizing radiation for the treatment of organic raw materials or feed used in the production of organic products; exclude hydroponic production; use living organisms and methods of mechanical production; feed the plants mainly through the soil ecosystem; are based on risk assessment and use preventive measures.

Wildlife hunting and fishing products are not considered organic products. Harvesting of wild plants and their naturally occurring parts in forests and farmland is considered organic production if: such areas have not been treated for at least five years with products prohibited by the Law of Ukraine «On Production and Management organic agricultural products and raw materials»; such harvesting does not affect the stability of the natural environment, the existence or conservation of plant species in the harvesting area.

Harvesting of wild algae and their parts that grow under marine natural conditions is considered organic production under the following conditions: algae growth areas are of high environmental quality, not contaminated with substances that are not allowed to be used in the production of organic products (raw materials), or other harmful to health human substances; such harvesting does not affect the stability of the natural environment, the existence or conservation of plant species in the harvesting area.

Industrial production of organic products within the green economy is made exclusively from organic raw materials grown on suitable land or in specially designated areas of organic production and raw materials. The area of production of organic products and raw materials is a place for production of organic products (raw materials), which is suitable for agroecological indicators for the production of organic products and organic raw materials of vegetable and animal origin. Assessment of the suitability of land (soils) for the production of organic products and raw materials, as well as the establishment of zones of production of organic products 
and raw materials is carried out by the State Inspectorate of Agriculture of Ukraine, with the opinion of the relevant scientific institutions, research institutes, quality and safety laboratories in accordance with the legislation. Assessment of the suitability of land (soils) is made taking into account the ecological-toxicological parameters of the agrochemical passport of the land plot and the results of chemical analysis of test plants grown on these soils at the time of the survey.

To produce organic products (raw materials) within the green economy, a natural or legal person of any organizational and legal form and any form of ownership who: has passed the conformity assessment of production of organic products (raw materials), has received a certificate of conformity is included in the Register of producers organic products (raw materials).

Conformity assessment of the production of organic products (raw materials) is carried out by the body for assessment of conformity of production of organic products (raw materials) in accordance with the rules of the procedure of attestation of conformity and with the technical regulations in accordance with the legislation on attestation of conformity. Organic products and raw materials must comply with the quality and safety indicators set out in the technical regulations. The production of organic products and / or raw materials is evaluated once every two years. To carry out the assessment, the person submits an application for the transition to the production of organic products to the body for assessment of conformity of production of organic products (raw materials). The assessment is conducted by a certification auditor and / or conformity assessment body specialist in accordance with the assessment plan and program that identifies the objects, the date of the assessment.

From the date of submission of the application of the established sample for the transition to production of organic products (raw materials), the transition period begins. Persons who decide to switch to organic production (raw materials) are subject to the following requirements: during the transitional period, the requirements established by the Law of Ukraine "On production and circulation of organic agricultural products and raw materials" apply; the length of the transitional period depends on the type of activity to be assessed and the conformity is confirmed, consistent with previous land use, environmental situation, production experience of the producer and for each person is established individually in the plan for the 
transition to organic production (raw materials); produce of annual crops is considered organic if a transitional period of at least 12 months has elapsed before the beginning of their growing season; if the transition period is longer than the specified transition period, the labeling of the product as «product at the transition to organic production» is allowed; products produced during the transition period are prohibited to be marketed as organic products with the appropriate marking and logo.

The issuance of a certificate of conformity on the basis of a decision that is made after the relevant conformity assessment procedures is a confirmation of the conformity of production of organic products (raw materials). Such confirmation is carried out by the conformity assessment body for the production of organic products (raw materials), which appoints a conformity assessment commission. Within one month from the date of receipt of the conclusion (report) of the certification auditor or a specialist of the conformity assessment body, the conformity assessment commission is obliged to decide whether to issue or refuse to issue a certificate of conformity. The grounds for refusal are: the establishment on the basis of the results of the inspection of non-compliance of production with the requirements of the Law of Ukraine "On the Production and Turnover of Organic Agricultural Products and Raw Materials" and technical regulations, the identification of false information in the documents submitted for assessment and confirmation of compliance.

In the case of a decision to issue a certificate of conformity, the person is issued a certificate of conformity of the established sample within three days from the date of making such decision, and the products can be labeled as organic product. The certificate is issued if all the ingredients of live or unprocessed agricultural products are organic and produced in accordance with the requirements established by the Law of Ukraine «On production and circulation of organic agricultural products and raw materials». The certificate is issued if the processed agricultural products have been completely produced in accordance with the requirements of the Law of Ukraine «On production and circulation of organic agricultural products and raw materials» and at least $95 \%$ of its ingredients are organic.

Upon receipt of the certificate, the person is included in the Register of Organic Producers (Raw Materials), which is published in the media. Natural or legal persons not listed in the Register of Organic Producers 
(Raw Materials) are not allowed to produce organic products and / or raw materials.

Organic producers are required to comply with the rules of production and circulation of organic produce and raw materials. General rules for the production and circulation of organic products and raw materials are laid down by the Law of Ukraine «On production and circulation of organic agricultural products and raw materials». Thus, natural or legal persons who have been granted the right to produce organic products (raw materials) are required to comply with the following general rules for the production of organic products and / or raw materials: to comply with the requirements of this Law and the rules of production and circulation of organic products and raw materials and / or wild plants, use only organic production methods and / or raw materials; to ensure the separation of the production of organic products (raw materials) from the production of inorganic products (raw materials), products of the transition period; use production technologies that prevent pollution or minimize any increase in environmental pollution; dispose of wastes and by-products of vegetable and animal origin in the process of organic production; to prevent the processes of disposal of pesticides and agrochemicals obtained by chemical synthesis in the territories where the production and storage of organic products (raw materials) is carried out; take into account the local and regional environmental status of territories when selecting products for production; minimize the use of non-renewable resources and external resources; to ensure the preservation and reproduction of soil fertility.

In the production of organic foodstuffs by processing a person who has been granted the right to produce organic products (raw materials), in addition to the above rules, they are required to comply with the following requirements: produce products mainly from ingredients of agricultural origin (except water and salt); not to use the organic ingredient together with the same ingredient in an inorganic form or ingredient in a transitional stage; not to use substances and technologies that restore the characteristics lost in the processing and storage of organic food, and correct negligence results in the processing of such products or otherwise mislead about the true nature of the product.

The general rules for the production of organic products (raw materials) of plant origin include: the use of methods that optimize the biological 
activity of soils, ensure a balanced supply of nutrients to plants, preserving the land and other natural resources necessary for the production of organic products (raw materials); introduction of soil protection technologies for growing crops that prevent erosion or other degradation processes from occurring in the soil; maintaining plant resistance by preventive measures by selecting appropriate species and varieties resistant to pests and diseases, appropriate crop rotation, mechanical, physical and biological methods of protection; increasing the population of beneficial insects, microorganisms and natural parasites as biological control of pests and plant diseases; use as a fertilizer of materials of microbiological, plant or animal origin, which are biodegradable; use only certified organic seeds and seedlings; fertilizers and soil improvers can only be used if permitted (except for mineral nitrogen fertilizers); in the event of a threat to plants, plant protection products may be used only if their use has been authorized; products for cleaning and disinfection in the production of crop products are used only if their use is authorized in organic production.

The producer, subject to the approval of the State Inspectorate of Agriculture of Ukraine, may produce organic and traditional (inorganic) crop production in one area: in the case of the production of perennial crops, the cultivation period of which is at least three years, if the varieties can be easily distinguished, subject to such conditions : the production concerned is part of the transition plan for the production of organic products (raw materials), provided that the transition period does not exceed five years; steps have been taken to ensure the continued separation of products received from each of the relevant units; at the end of the harvest, the manufacturer shall inform the inspection body of the exact quantity of the harvest collected in the relevant units and shall inform him of the measures taken to separate the products; if the relevant areas are intended for scientific research; if the land is used solely for grazing.

In the case of parallel production, an economic entity that produces organic products, raw materials, separates land, animals and products used or produced with organic parts and maintains appropriate records to confirm such separation. In exceptional cases, with the consent of the State Inspectorate of Agriculture of Ukraine, during production of organic products, raw materials may be used for traditional products, raw materials (except for products containing GMOs derived from GMOs or obtained 
through GMOs), and products and raw materials in transition for such goals: as plant protection products; as fertilizers and soil improvers; as inorganic feed materials of vegetable, animal and mineral origin; as feed or process additives; as products for the purification and disinfection of ponds, cages, structures and installations for the production of livestock products; as products for cleaning and disinfection of facilities and plants used for the production of plant products, includin facilities for storing such products.

The permissible volumes and the list of inorganic products, substances, products obtained in the transitional period, which in exceptional cases can be used in the production of organic products (raw materials), for each of the product categories, substances shall be established by the Cabinet of Ministers of Ukraine.

\section{References:}

1. Aleskerova, Y., \& Hutsalenko, O. (2019). Agricultural organic market in Ukraine. Ekonomika. Finans. Management: actual sciences and practices, no. 8, pp. 15-22.

2. Aleskerova, Y., Hutsalenko, O., \& Vilchynska, N. (2019). Agricultural organic production in the world. Polsh journal of science, no. 20, vol. 2, pp. 5-14.

3. Aleskerova, Y., Mulyk, T., \& Fedoryshyna, L. (2018). Improving credit protection analysis methods reports of main agricultural enterprises. Baltic Journal of Economic Studies, vol. 4, no. 2, pp. 1-7. DOI: https://doi.org/ 10.30525/2256-0742/2018-4-2-1-7.

4. Aleskerova, Y., Fedoryshyna, L., \& Koval, N. (2018). Features of loan security for the reproduction of fixed assets for agricultural purposes. Baltic Journal of Economic Studies, vol. 4, no. 4, pp. 1-5. DOI: https://doi. org/10.30525/2256-0742/2018-4-2-1-7.

5. Aleskerova, Yuliia, \& Fedoryshyna, Lidiia (2018). Analysis of investment activities of enterprises of Ukraine Economic system development trends: the experience of countries of Eastern Europe and prospects of Ukraine: monograph / edited by authors. - Riga, Latvia: "Baltija Publishing”. DOI: https://doi.org/ 10.30525/978-9934-571-28-2.

6. Aleskerova, Y. (2015). Insuarance policy and its models in relation to agriculture. Global and national economic problems, no. 4, pp. 760-766.

7. Aleskerova, Y. V. (2015) Economy agriculture countries: Myanmar. The journal of economic sciences: theory and practice, vol. 72, no 2, pp. 24-31.

8. Frydlova, M., \& Vostra, H. (2011). Determinants influencing consumer behaviour in organic food market. Acta Univ. Agr. Silvicult. Mendelianae Brunensis. Vol. 59 (7), pp. 111-119.

9. Grzelak, P., \& Maciejczak, M. (2013). Comparison between the United States and Poland of consumers' perceptions of organic products. Studies in agr. economics. Vol. 115 (1), pp. 47-56. 
10. Gubbuk, H., Polat, E., \& Pekmezci, M. (2004). Organic fruit production in Turkey. J. Fruit ornamental Plant Res. Vol. 12 (spec.ed.), pp. 23-29.

11. Smoluk-Sikorska, J., \& Luczka-Bakula, W. (2013). Sale of organic food in specialist and general retail grocery outlets - a comparative analysis. Acta scientiarum Polonorum: Oeconomia, no. 12 (1), pp. 35-44.

12. Westercamp, C., Nouri, M., \& Oertel, A. (2015). Agricultural Credit: Assessing the Use of Interest Rate Subsidies. AFD Sustainable Development Department, 165. Retrieved from: https://www.afd.fr/sites/afd/files/importedfiles/29-VA-A-Savoir.pdf

13. Official website of the Guelph University (2018). "University of Guelph Introduces New Organic Agriculture Certificate to Enhance Educational Opportunities for Students". Available at: https://www.uoguelph.ca/oac/news/university-guelphintroduces-new-organic-agriculture-certificateenhanceeducational (Accessed 1 July 2018).

14. Brintseva, O., Hutsalenko, O., \& Dmitruk, S. (2017). The role of socially responsible marketing in the reproduction of the human capital and reduce of its fiktivization processes. Baltic Journal of Economic Studies, vol. 3, no. 5, pp. 33-37. DOI: http://dx.doi.org/10.30525/2256-0742/2017-3-5-33-37 